\section{France waits in the wings}

THE loss of the space shuttle Challenger last week has caused some heart-searching in France about the future of Hermes, the French-inspired project for a miniature space-plane to sit atop a magnified version of the European space launcher, Ariane. But according to Frédéric d'Allest, director-general of the French space agency CNES, man's presence in space is essential, so the development of Hermes will certainly continue.

The French plan has not yet been approved by the other European partners in Ariane, notably West Germany, Britain and Italy. Hermes would carry mainly people, with a small amount of cargo $(4,500 \mathrm{~kg}$ compared with the shuttle's $20,000 \mathrm{~kg}$ ). Heavier cargo would be carried separately, but both would be lifted into space by Ariane-5, a liquid hydrogenfuelled version of Ariane now under development. Although safety has of course been a major consideration, critics now point out that Hermes could be more dangerous than the shuttle, because it would have only one engine.

Nevertheless, given enough warning, Hermes could use an auxiliary escape rocket to fire the space-plane upwards and out of danger more quickly than could the shuttle sitting astride its main fuel tank.

In fact, more than two years ago, Hermes designers at Aerospatiale, one of the principal French aerospace companies, were designing the escape rocket for Hermes so that it functions in what seems to be an exact analogue of last week's accident, the explosion of the second stage at the moment of maximum dynamic pressure. The designers concluded that a small rocket under the body of Hermes, capable of giving it an $8 \mathrm{~g}$ vertical accelaration, could save it.

This week, French space specialists would draw no firm conclusions from the shuttle disaster. On present plans, Hermes' first manned launch will take place in 1995 , on what will be only the third test flight of Ariane 5, a prospect that might now appear foolhardy. According to d'Allest, the dangers of entering space can be compared with those of entering a radiation zone in a nuclear reactor. The comparison may be more than apt, as increased public pressure for radiation protection has led to improved safety systems and correspondingly increased nuclear construction costs; similarly, the public unacceptability of an accident like last week's may well do the same for Hermes and other planned space-planes.

In the now long-running competition between the shuttle and present versions of Ariane, the commercializer of the European launcher, Arianespace, was not prepared last week to comment on the impact of the shuttle disaster. On the face of it, it would seem that satellite companies might now favour unmanned launchers, particularly as there is now a long queue of satellites waiting to be launched in what was to be the shuttle's busiest-ever year. But satellites that have been prepared for the shuttle would have to be modified to make them suitable for launching on Ariane or similar vehicles. In any case, capacity on Ariane is almost entirely taken up with a $£ 1,000$ million back$\log$ of contracts. Although a second launch site is being opened at Kourou, French Guiana, next month, Arianespace foresees no more flight opportunities in 1986, just one in 1987 and three in 1988.

Moreover, Ariane has its own difficulties. The last flight (V15) led to destruction as the result of a leaking fuel valve. With that problem now supposed solved after a slight design modification, Ariane V16 is sitting on site in Kourou awaiting a replacement for a water cooling tank, which was found to be cracked and leaking just before the planned launch on 11 January. V16 should now fly, carrying the first French Earth observation satellite SPOT and a Swedish scientific satellite Viking, on 21 February.
Marine satellites

\section{Japan offers free data}

\section{Tokyo}

DATA from Japan's marine observation satellite MOS-1, due to be launched next year, are available for anyone willing and able to participate in the verification programme for the satellite. Japan's National Space Development Agency (NASDA) will supply MOS-1 data free of charge provided the data are used only for peaceful purposes, are valuable from a scientific and technical viewpoint and are "useful to NASDA", which means helping in evaluation of the radiometric and geometric performance of the satellite. Such is the gist of a guideline distributed by NASDA to organizations in 11 countries, including the European Space Agency (ESA). The deadline for proposals to NASDA is the end of February.

MOS-1 will view the whole surface of the Earth every 17 days and, with its three scanners and data-collection system is, theoretically, capable of transmitting more information than the Landsat satellites now in use. But coverage will be restricted by the availability of suitably equipped monitoring stations and the battery power of the satellite. Apart from NASDA's Earth Observation Center in Japan, which can monitor the satellite over north-east China, Taiwan, Korea, Japan and the eastern Soviet Union, agreement has just been reached with Thailand to build a monitoring station on the outskirts of Bangkok at a cost to Japan of 800 million yen (about $£ 3$ million). This station will cover the Philippines, Indonesia, east India and western China.

NASDA also hopes that ESA's station at Las Palmas in the Canary Islands will monitor the satellite and that Australia may upgrade its satellite stations to receive MOS data. But NASDA officials stress that MOS-1 is only experimental, with limited power. The satellite's power should be adequate if data are transmitted only during the day, but night-scanning will drain its batteries, according to Yasushi Horikawa, director of NASDA's Earth Observation Satellite Program.

MOS-1 scanners will be trained largely on the sea where its high resolution $(50 \mathrm{~m})$ multi-spectrum electronic self-scanning radiometer and visible and thermal infrared radiometer will provide information on ocean currents, red tides, pollution and volcanic eruptions, while its microwave scanning radiometer will monitor atmospheric water vapour content, sea ice and snow distribution.

By the time it is launched early in 1987, MOS-1 will have run up a bill of Y56,000 million ( $£ 200$ million). Its expected mission life is two years. 